УДК 339.3

DOI 10.31882/2311-4711.2019.25.16

\author{
Миролаев Александр Андреевич \\ магистрант 2-го года обучения, направление «Торговое дело», магистерская программа \\ «Организация и технология торгового бизнеса»,
}

\author{
Петров Роман Андреевич \\ магистрант 2-го года обучения, направление «Торговое дело», магистерская программа \\ «Организация и технология торгового бизнеса», \\ Российский экономический университет имени Г.В.Плеханова, \\ Российская Федерация, г. Москва, 117997, Стремянньй пер., 36 \\ E-mail: alexandermirolaev@gmail.com
}

\title{
ИНТЕГРАЦИЯ ТОРГОВЫХ СТРУКТУР С ИСПОЛЬЗОВАНИЕМ ИНСТРУМЕНТОВ ФРАНЧАЙЗИНГА
}

Аннотация. Предлагаемое исследование отражает специфику развития интегрированных торговых структур в сфере розничной торговли на основе применения концепции франчайзинга. Современная специфика работы организаций отрасли подразумевает необходимость использования различных инструментов с целью сохранения рыночных позиций. Одним из них является обратный франчайзинг, транслирующий основные элементы моделей франчайзинга, но имеющий некоторые отличия в экономических отношения между партнерами. Статья выполнена под научным руководством Зверевой А.О., к.э.н., доц., доцента кафедры торговой политики ФГБОУ ВО РЭУ им. Г.В. Плеханова

Ключевые слова: франчайзинг, коммерческая концессия, обратный франчайзинг, розничная торговля, интегрированные торговые структуры

Введение. В практике современного ритейла интеграция является необходимым способом выживания в конкурентной борьбе, а ведение бизнеса с использованием модели франчайзинга все более востребованным. Такой способ партнерских связей использует делегирование прав на средства индивидуализации товаров и услуг (к ним относят товарный знак, знак обслуживания), фирменный стиль, технологии ведения торгового бизнеса [1]. Иногда передаются права на использование определенной коммерческой информации, которая может предоставить партнеру дополнительные преимущества. Довольно часто владелец франшизы берет на себя обязательства по оказанию консультаций в сфере становления и ведения рассматриваемого торгового бизнеса, обеспечению его технической поддержки, приобретению необходимого торгового оборудования, или разработке планировочных решений $[2,3]$.

Основная часть. В современных условиях франчайзинг является востребованным инструментом интеграции торговых структур. Конечно цифровые тренды отрасли, использование технологий омниканальности, «online-to-offline» предоставляют торговым структурам значительные конкурентные преимущества [4].
Однако, интеграция (объединение) или формирование длительных партнерских связей может служить альтернативным инструментом выживания на рынке. Предоставляя права использования интеллектуальной собственности посредством коммерческой концессии, или же модель ведения бизнеса в целом, франчайзер посредством сети расширяет охват и собственную долю рынка. Этот факт служит аргументом в конкурентной борьбе за потребителя; особенно это важно в сфере розничной торговли, где монополизация рынка и рост доли торговых сетей увеличивается из года в год. Также франчайзинг является дополнительным источником формирования прибыли для владельца прав, то есть франчайзера [5].

Франчайзинг в сфере розничной торговли стал популярным благодаря ряду достоинств, к которым можно отнести более широкий охват потребительской аудитории, повышение привлекательности предприятия-партнера за счет авторитета франчайзера, внедрения новых технологических (как правило, более дорогостоящих) решений и трансляции их франчайзером для своих партнеров. Последний фактор является чрезвычайно важным в условиях проникновения цифровых технологий во все сферы деятельности, в том числе в ритейл. 
В сфере розничной торговли предприниматель, приобретая франшизу, как правило, получает бизнес-модель, которая уже апробирована. В первую очередь определена ассортиментная и ценовая политика, стандартизовано торговое оборудование, что обеспечивает востребованность и потребительский спрос. Довольно часто именно в ритейле применяется модель так называемого обратного франчайзинга. Стандартная схема франчайзинга, иначе говоря, прямой франчайзинг предполагает ряд финансовых расчетов, выплату паушального взноса, роялти, отчислений в рекламные фонды. Обратный франчайзинг подразумевает, конечно, наличие у франчайзера определенно авторитета, имени, зарегистрированных товарных знаков, известность в определенной аудитории [6].

Однако в данном случае экономия средств при расчетах между партнерами связана со спецификой экономической организации отношений, когда отчисления по итогам работы осуществляются в адрес франчайзи, в виде вознаграждения со стороны франчайзера. Наряду с данным фактом владелец франшизы планирует основные вопросы, связанные с товарным обеспечением, формирует товарные ресурсы, осуществляет подбор поставщиков. Франчайзи фактически получает товар на реализацию, не оформляя переход права собственности.

При поддержке франчайзера предприниматель (франчайзи) имеет возможность уделить основное внимание операционной деятельности, не вникая в стратегические аспекты продвижения бренда. Но, конечно, все основные экономические аспекты, в том числе вопросы выполнения налоговых обязательств перед государством должны соблюдаться всеми участниками таких взаимоотношений [7].

С точки зрения потребителя распространение франчайзинговых взаимоотношений так же предоставляет преимущества. Благодаря территориальному распространению интегрированных торговых организаций потребители получают возможность приобретения востребованного ассортимента товаров, обеспеченных гарантией качества со стороны владельца франшизы. Обратим внимание на негативные моменты при реализации коммерческой концессии. Принимая к выполнению условий договора, которые разрабатывает франчайзер, партнер зачастую лишен самостоятельности в принятии решений [8]. Например, довольно часто франчайзи вынуждены следовать ограничениям в части формирования ассортимента, теряя значительные средства на доставке товаров за счет удаленности поставщиков в случае регионального развития франшизы. Известны примеры, когда с учетом востребованности со стороны потребителя франчайзи готов предложить инновационные решения для покупателя (допустим, использование мобильно приложения в качестве платформы организации взаимоотношений). Однако инертность со стороны владельца прав этому препятствует.

В свете влияния факторов внешней среды можно отметить некоторое сокращение предлагаемых концепций франчайзинга в сфере розничной торговли. Негативные тенденции вынудили наиболее слабые компании свернуть партнерский бизнес. Этот тренд особенно заметен в условиях различающейся товарной специализации, особенно в предложении франшиз магазинов одежды, обуви и других им подобных. Перечисленные игроки наиболее зависимы от общей негативной экономической ситуации в стране, а также подвержены давлению со стороны транснациональных интернет-ритейлеров. В противовес обозначенному факту активно развиваются франшизы неспециализированных предприятий $[9,10]$.

К ним относят предприятия, реализующие концепцию франчайзинга по реализации продуктов питания, магазины фиксированных цен, а также аптеки. Не смотря на стагнацию крупные интегрированные сети розничной торговли увеличили трафик и основные экономические показатели, продемонстрировав безубыточную деятельность [11]. Таким образом, реализация франчайзинговых взаимоотношений является возможным путем развития предприятий розничной сферы в условиях влияния внешних факторов.

Заключение. Подводя итог резюмируем: благодаря экономическим взаимоотношениям хозяйствующих субъектов, использующих модель франчайзинга, современные организации розничной сферы получает возможность развития даже в условиях нестабильной внешней среды. В целом, активность в реализации отношений с применением договора коммерческой концессии демонстрируют предприятия различных сфер, в том числе предприятия розничной торговли. Многие из них избегают открытия новых собственных предприятий, уменьшая хозяйственные риски за счет развития франчайзинговой сети.

В ввиду отраслевые специфики востребованным инструментом является обратный франчайзинг, а подобная практика организации торговой деятельности вызывает интерес потенциальных инвесторов. Принятие взвешенного решения при приобретении франшизы, развитие интегрированного торгового бизнеса является способом сохранения рыночных позиций в условиях нестабильного макроэкономического воздействия. 


\title{
Список использованных источников
}

1. Голубцова Е.В., Зверева А.О., Литовкина В.Д. Франчайзинговые взаимоотношения в розничной торговле в контексте практики налогообложения//Российский экономический интернет-журнал. 2018. № 1. С. 11.

2. Глубокова Н.Ю., Егорова Л.И. Налоговый контроль как элемент внутрифирменной контрольной среды // Экономика и предпринимательство. 2014. № 12-3 (53). С. 577-580.

3. Голубцова Е.В. Налоговое регулирование внешнеторговой деятельности в Российской Федерации: учебное пособие. -М.: ГОУ ВПО «РЭУ им. Г.В. Плеханова», 2011. -80 с.

4. Юдникова Е.С., Ильяшенко С.Б. Вектор развития инновационного потенциала в торговле на основе внедрения «online-to-offline» коммерции // Российское предпринимательство. 2018. Т. 19. № 11. С. 3313-3322

5. Дюжов А.В. Экономико-правовые аспекты учетной политики на примере раздельного учета по НДС // Инициативы XXI века. 2014. № 4. С. 14-16.

6. Колчин С.П. Налогообложение: Учеб. пособие по программе и аттестации профессиональных бухгалтеров. Базовый курс. -М.: Издательский дом БИН-ФА, 2010. -156 с.

7. Ахмадеев Р.Г., Косов М.Е. Эффективность налоговой политики в сфере инноваций // Финансовая жизнь. 2017. № 1. С. $74-78$.

8. Депутатова Е.Ю., Ильяшенко С.Б. Вопросы изучения покупательского спроса и оценки емкости рынка // Экономика и предпринимательство. 2017. № 8-3 (85). С. 56-61.

9. Малицкая В.Б. Анализ финансовых активов как одной из основных групп показателей финансового состояния организации/ В.Б. Малицкая// Аудит и финансовый анализ. 2008. №1. С. 89-96.

10. Зверева А.О., Леонова Ю.Г. Использование модели обратного франчайзинга в розничном торговом бизнесе// Экономика и предпринимательство, 2017, № 7 (84), стр.1189-1193.

11. Мастеров А.И. Управленческий учет и анализ ассортиментной и ценовой политики как инструмент повышения эффективности деятельности организации // Международный бухгалтерский учет. - 2015. - №9. - С. 27-39.

\section{Mirolaev Alexander Andreevich}

Student of Master Degree, the direction of "Trade", Master Program «Organization and technology of trade business»,

\author{
Petrov Roman Andreevich \\ Student of Master Degree, the direction of "Trade", \\ Master Program "Organization and technology of trade business», \\ Plekhanov Russian University of Economics \\ Russian Federation, 117997, Moscow, Stremyanny lane, 36 \\ E-mail: alexandermirolaev@gmail.com
}

\section{INTEGRATION OF TRADING STRUCTURES WITH FRANCHISING}

Summary. The proposed study reflects the specifics of the development of integrated retail trade structures based on the use of the franchise concept. The modern specificity of the work of industry organizations implies the need to use various tools in order to maintain market positions. One of them is reverse franchising, which broadcasts the basic elements of franchising models, but has some differences in economic relations between partners.

Keywords: franchising, commercial concession, reverse franchising, retail, integrated trading structures 